\title{
Segura a Onda: experiência brasileira de mapeamento de iniciativas cidadãs no enfrentamento da pandemia da Covid-19
}

\author{
Segura a Onda (Flatten the Curve): Brazilian experience on \\ mapping citizen initiatives to deal with pandemic Covid-19
}

\author{
Anne Clinio ${ }^{a}$ * (D) \\ Beatriz Cintra Martins ${ }^{b}$ (D) \\ Christiana Metzker Netto ${ }^{c}$ \\ Luis Eduardo Tavares ${ }^{d}$ (D) \\ Maria de Lourdes Silva de Oliveira e (D) \\ Ricardo Marques da Silva Martins Guimarães f
}

\begin{abstract}
RESUMO: O relato busca socializar a experiência da criação e manutenção da plataforma Segura a Onda, projetado como repositório de informações relevantes e qualificadas sobre iniciativas cidadãs que surgiram no País como estratégia de enfrentamento da pandemia. Primeiramente, introduz brevemente o contexto da crise sanitária no Brasil na sua relação com a informação. Em seguida, descreve seu método de trabalho para curadoria e publicação de informações, organizadas em fóruns temáticos, e apresenta as ações diretas realizadas com o objetivo de gerar maior dinamismo, diálogo e interação, abordando ainda os desafios vividos no processo de auto-organização de uma iniciativa cidadã promovida por um grupo de colaboradores voluntários sem apoio financeiro. Por fim, concluiu-se que, mesmo com a divulgação pelas redes sociais digitais populares entre os brasileiros, sua difusão ficou limitada, na medida em que essas plataformas exigem pagamento de taxas de impulsionamento para ampliar a visibilidade das postagens. No entanto, uma contribuição indireta da plataforma é a documentação de iniciativas cidadãs durante esse período de modo a constituir, em alguma medida, memória de processos sociais. Assim, vislumbra-se que este relato de experiência pode contribuir com debates e pesquisas futuras sobre a estratégia de produção de mapeamentos de iniciativas cidadãs, seu alcance e impacto.
\end{abstract}

Palavras-chave: Inovação Cidadã; Segura a Onda; Pandemia, Auto-Organização.

ABSTRACT: The report aims to socialize the experience of creating and maintaining Segura a Onda platform, designed as a repository of relevant and qualified information on citizen initiatives that emerged in the country as a strategy to face the pandemic. First, it briefly introduces the context of the health crisis in Brazil regarding information. Then, it describes the work method for curating and publishing information, organized in thematic forums. It presents the direct movements carried out with the objective of generating greater action, dialogue and interaction. As a self-organization of a citizens' initiative promoted by a group of volunteers with no financial support, the group experienced many challenges in the process. The conclusion shows that, even with the dissemination on the most popular

\footnotetext{
a Projeto Rural Sustentável Caatinga, Rio de Janeiro, RJ, Brasil.

b Centro Multidisciplinar de Pesquisas em Criações Colaborativas e Linguagens Digitais, Programa Interunidades de Pós-Graduação em Estética e História da Arte, Universidade de São Paulo, São Paulo, SP, Brasil.

' Fundação Telefônica Vivo, São Paulo, SP, Brasil.

d Fundação Escola de Sociologia e Política de São Paulo, SP, Brasil.

e Pesquisadora independente de espaços de comum urbano e autogestão e consultora de planejamento e estratégia de comunicação.

${ }^{f}$ Ativista, pesquisador e desenvolvedor de tecnologias abertas no GypsyLab8, São Paulo, SP, Brasil.

*Correspondência para/Correspondence to: Anne Clinio. E-mail: anneclinio@gmail.com.

Recebido em/Received: 15/08/2020; Aprovado em/Approved: 04/11/2020.

Artigo publicado em acesso aberto sob licença CC BY 4.0 Internacional $($ )(i)
} 
social networks among Brazilians, the diffusion of the content was limited, as these platforms require payment of boost fees to increase the visibility of the posts. However, an indirect contribution of the platform is the documentation of citizen initiatives during this period to constitute, to some extent, memory of social processes. Thus, it is envisaged that this experience report can contribute to future debates and research on the strategy of producing mappings for citizen initiatives, their scope and impact.

Keywords: Citizen Innovation; Segura a Onda; Flatten the Curve; Pandemic, Self-Organization.

\section{INTRODUÇÃO}

O presente artigo é um relato da experiência da plataforma Segura a Onda', um guia on-line de iniciativas cidadãs surgidas como resposta brasileira à crise sanitária deflagrada pela pandemia global do novo coronavírus (Covid-19), decretada pela Organização Mundial da Saúde (OMS) em 11 de março de 2020. A plataforma foi lançada no dia 27 de março de 2020, um mês após a confirmação do primeiro caso da doença no Brasil, e foi articulada por uma rede autônoma de voluntários e entidades sociais. A Segura a Onda se estruturou como capítulo brasileiro da plataforma Frena La Curva ${ }^{2}$, criada na Espanha e expandida para 18 países, cada qual adaptando a iniciativa às características e suas realidades locais.

O relato busca socializar a experiência da criação e manutenção da Segura a Onda, subsidiando outras iniciativas similares e o debate sobre estratégias de fortalecimento de redes de solidariedade e colaboração em situações de crise a partir de estratégias de sistematização e difusão de informações em plataformas on-line. Na primeira parte, o artigo descreve a experiência da Segura a Onda como grupo de colaboradores voluntários e os desafios da sua própria auto-organização, percorrendo temas como método de trabalho, estratégias de atuação, trabalho de curadoria no formato de fóruns temáticos e as ações diretas realizadas a partir da identificação da necessidade de maior gerar dinamismo, interação e diálogo com o cotidiano. Em seguida, apresentamos reflexões sobre os limites e possibilidades da iniciativa em curso, compartilhando experiências aprendidas até o momento que podem subsidiar outras pesquisas sobre o tema.

Em todas as partes, a emergência sanitária global se situa no entroncamento de outras crises - especialmente a ambiental, na medida em que o desequilíbrio ecológico acelera mudanças climáticas com alta probabilidade de gerar novas pandemias. No entanto, 0 Brasil se tornou em junho o segundo país em número de contágios e de mortes e o principal epicentro na América Latina (Chade, 2020) por conta da grave crise institucional entre os poderes Legislativo, Executivo e Judiciário em todos os níveis da administração pública. Esta crise se agrava, em grande medida, mas não exclusivamente, por ações de desinformação e também pela falta de acesso à informação relevante, de interesse público.

Não se trata apenas da descoordenação das ações governamentais, há um investimento deliberado, especialmente por parte do Governo Federal, representado pelas ações e declarações do presidente Jair Bolsonaro. Ele nega o conhecimento científico acumulado nos últimos meses sobre a doença, menospreza a sua gravidade, investe na produção de medicamentos comprovadamente ineficazes e desrespeita sistematicamente normas sanitárias recomendadas pela OMS, atuando deliberadamente contra as medidas de prevenção do contágio. Nos níveis estaduais e

\footnotetext{
'Disponível em https://seguraaonda.com.br/

2 Disponível em https://frenalacurva.net/
} 
municipais, se repetem tomadas de decisões sobre reabertura de comércio, escolas e locais públicos desencontradas das orientações sanitárias.

Este cenário promove, dia após dia, uma tragédia social crescente, sem precedentes e aparentemente sem horizonte próximo de saída. No campo da saúde, acumulam-se mais de 3 milhões de contágios e a marca de 100 mil mortos em 8 de agosto de 2020. No campo social, já éramos, antes da pandemia, 13,5 milhões de pessoas vivendo em condições de extrema pobreza (Nery, 2019) e acumulamos os reflexos econômicos da crise sanitária.

Por outro lado, registram-se iniciativas de enfrentamento da pandemia com base na coordenação de esforços, diálogo com o conhecimento científico, observação das orientações de organizações internacionais, aprendizado com a experiência e colaboração com países que primeiramente enfrentaram o novo coronavírus. $\mathrm{Na}$ contramão do discurso anti ciência que caracteriza as ações do Governo Federal, cientistas brasileiros, liderados pelas pesquisadoras Ester Sabino (Faculdade de Medicina da Universidade de São Paulo) e Jaqueline Goes de Jesus (no Instituto de Medicina Tropical de São Paulo), foram os primeiros a sequenciar e compartilhar abertamente o genoma do novo coronavírus (Dantas, 2020) detectado em São Paulo. Ainda no campo da Saúde Pública, instituições como a Fundação Oswaldo Cruz (Fiocruz) e o Sistema Único de Saúde (SUS) vêm desempenhando um papel fundamental no atendimento à população. O SUS, apesar da carência histórica de recursos, agravada pela Emenda Constitucional 95 do Teto dos Gastos Públicos, vem atendendo à população, especialmente a de baixa renda, graças ao seu modelo de acesso integral, universal e gratuito - uma excepcionalidade brasileira.

Contrastando com o "bater de cabeças" das instâncias governamentais, surgem espontaneamente centenas de iniciativas oriundas de indivíduos, coletivos e da sociedade civil organizada que, a partir da identificação de problemas de ordem prática, da sobrevivência e da subsistência durante a pandemia, articulam voluntários, conhecimentos e recursos para conceber e operacionalizar soluções, ainda que limitadas, aos desafios enfrentados pela população. Ao sentir a ameaça da pandemia do novo coronavírus e seus primeiros efeitos, parte da sociedade brasileira, de modo espontâneo e independente de ações estatais, mobilizou organizações de base e vizinhança para o enfrentamento da crise, principalmente nos territórios e grupos sociais com maior potencial de serem afetados. São inúmeros os esforços coletivos. São indivíduos, coletivos e segmentos da sociedade civil organizada - englobando projetos sociais, fundações, organizações do terceiro setor, igrejas e associações comunitárias, de bairro, profissionais, comerciais, religiosas, recreativas - que estruturam e coordenam ações para pensar e produzir procedimentos de controle da pandemia e soluções emergenciais que tomam a forma de redes auto protetivas e de ajuda mútua - um fenômeno observado em cenários de catástrofes em que o corpo social reage às ameaças de sua vitalidade.

Trata-se de empreendimentos surgidos do impulso de agir coletivamente em defesa da própria sobrevivência na medida em que a segurança individual só é alcançada através de ações em prol da segurança comum. Tais soluções são resultado do conhecimento e do trabalho de muitas pessoas que, colocadas a serviço da coletividade, não impedem o elevado número de óbitos, mas amenizam, de diferentes formas, o cotidiano da crise. Essas redes ${ }^{3}$ interconectam uma pluralidade de pessoas

\footnotetext{
3 Em princípios de abril, uma centena organizações da sociedade civil, incluindo a Segura a Onda, se articularam no movimento "Sociedade Contra o Corona\#", capitaneada pelo Pacto Pela Democracia, com a proposta de reunir as organizações comprometidas a mapear as necessidades de comunidades em situação de vulnerabilidade, mobilizar
} 
que coordenam trabalhos coletivos, compartilham conhecimento e produzem comunicação, logística e tecnologia em ações como arrecadação de doações e entrega de mantimentos para populações vulneráveis, apoio aos diferentes trabalhadores e profissionais prejudicados pela pandemia, combate à violência de gênero durante 0 isolamento social, amparo psicossocial, mutirão de acolhimento de enlutados ou visibilização das vítimas, produção de tecnologias hospitalares etc.

Neste cenário complexo, um dos primeiros desafios frente à escalada da pandemia foi reunir e sistematizar informações sobre essas iniciativas a fim de, por um lado, facilitar o acesso do público a elas e, por outro, possibilitar seu fortalecimento e articulação em redes de colaboração e solidariedade em todo território nacional. A plataforma on-line Segura a Onda surge como mais uma iniciativa cidadã, tendo como principal objetivo reunir, sistematizar e disseminar as ações da sociedade civil, dando especial atenção à indexação de conteúdos, na perspectiva de facilitar a sua recuperação, e o trabalho curatorial para garantir qualidade da informação. Registramos aqui a existência de, pelo menos, dez outros mapeamentos on-line de iniciativas empreendidas pela sociedade civil, destacando: Emergência Covid-194 (Grupo de Institutos Fundações e Empresas - GIfe); Mapa Colaborativo (Universidade Federal do ABC - UFABC); Mapa Corona nas Periferias ${ }^{6}$ (Instituto Marielle Franco); Mapa do acolhimento (Nossas); Mapa Solidário ${ }^{8}$ (voluntários ligados a Universidade Tecnológica Federal do Paraná UTFPR); ProtegeBR ${ }^{9}$ (Olabi); SOMOS MUITXS ${ }^{10}$ (não identificado); Urbanismo Contra o Corona"1 (rede de profissionais e estudantes, arquitetos de ofício, militantes de movimentos, representantes de instituições e entidades).

\section{A EXPERIÊNCIA DA SEGURA A ONDA}

Nos dias que antecederam a formação da Segura a Onda em meados de março de 2020, a pandemia se aproximava do Brasil e alguns acontecimentos começavam a despertar preocupação. Além das notícias do número crescente de contaminados e mortos na Europa, principalmente na Itália, eram registrados os primeiros casos em território nacional, oriundos de viagens e festas promovidas por pessoas de classes sociais mais privilegiadas, incluindo o contágio de boa parte da comitiva presidencial em viagem aos Estados Unidos. As perspectivas de alastramento da doença começavam a se manifestar. Se os primeiros casos de contágio foram registrados nas camadas mais elitizadas da população, logo surgiram os óbitos entre os mais pobres e desassistidos. Tornou-se um caso emblemático da desigualdade social do país o primeiro óbito registrado no Rio de Janeiro, o de uma empregada doméstica de 63 anos, que contraiu o coronavírus de sua empregadora, uma moradora do bairro nobre do Leblon, que

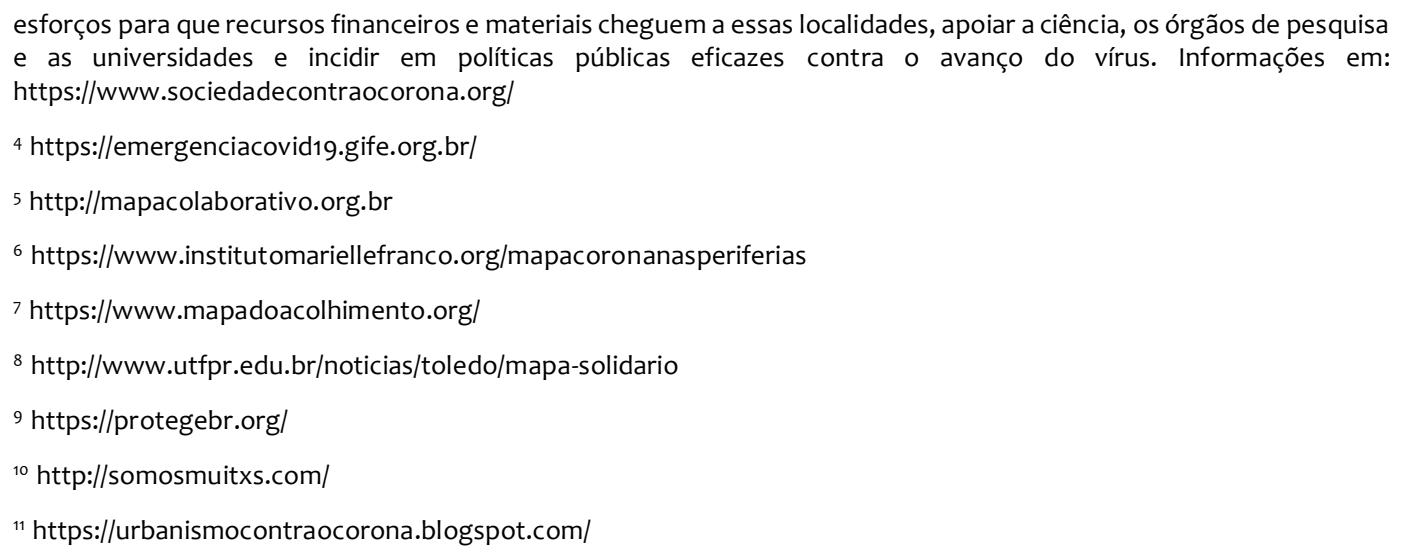


retornou da Itália com sintomas da doença, mas não dispensou a funcionária. (Melo, 2020).

Neste momento, concorriam dois fenômenos. Por um lado, havia a proliferação de informações desencontradas, em grande parte falsas, provenientes de fontes incógnitas que ampliavam a incerteza, ansiedade e pânico, tais como notícias sobre conspirações chinesas para dominar o mundo, falsos remédios, rumores de desabastecimento de bens essenciais etc. Por outro lado, começava a campanha \#FicaemCasa nas redes sociais para promover o distanciamento social como forma prioritária de prevenção de novos contágios. Foi neste contexto que um grupo até então disperso de pessoas e entidades sociais começaram a convergir em torno da proposta de implantação de uma versão brasileira da ação coletiva recém lançada na Espanha, a "Frena La Curva" (Freia a Curva, em português).

A plataforma espanhola havia sido lançada no dia 14 de março de 2020 e pretendia criar uma rede internacional para o enfrentamento da pandemia. A partir de um grupo de Telegram chamado "Frena la Curva América Latina", os primeiros voluntários brasileiros foram apresentados à iniciativa e entraram em contato com a rede que, naquele momento, já contava com grupos na Colômbia, México, Costa Rica e Equador, além dos recém chegados vindos do Uruguai, Argentina e Brasil. A proposta foi considerada relevante por oito voluntários brasileiros que começaram a criar estratégias para operacionalizá-la, motivados pela necessidade de ofertar à população informações confiáveis sobre as ações coletivas já em curso.

Um dos primeiros passos para a implementação da versão brasileira na web era o registro de um domínio. O nome "Frena la Curva" (Freia a curva em português) faz referência ao gráfico comparativo entre as curvas de contágio e da capacidade de atendimento hospitalar que foi amplamente disseminado para explicar a importância do isolamento social para distribuir em um período mais longo de tempo a ocorrência de casos, evitando a sobrecarga dos sistemas de saúde. Esta representação visual foi apresentada pela primeira vez em artigo científico que trata de estratégias comunitárias contra a pandemia de influenza, publicado em 2007 pelo Centers for Disease Control and Prevention (CDC, 2007), mas se popularizou em $2020 \mathrm{com}$ a sua publicação pela revista The Economist em 29 de fevereiro (The Economist, 2020). A partir de então, o gráfico se tornou, em todo mundo, um símbolo da necessidade de ações coletivas e de isolamento social, convertendo-se em parte da logomarca e estratégia de comunicação da nascente rede internacional Frena La Curva.

Imagem 1: A curva de contágio como inspiração

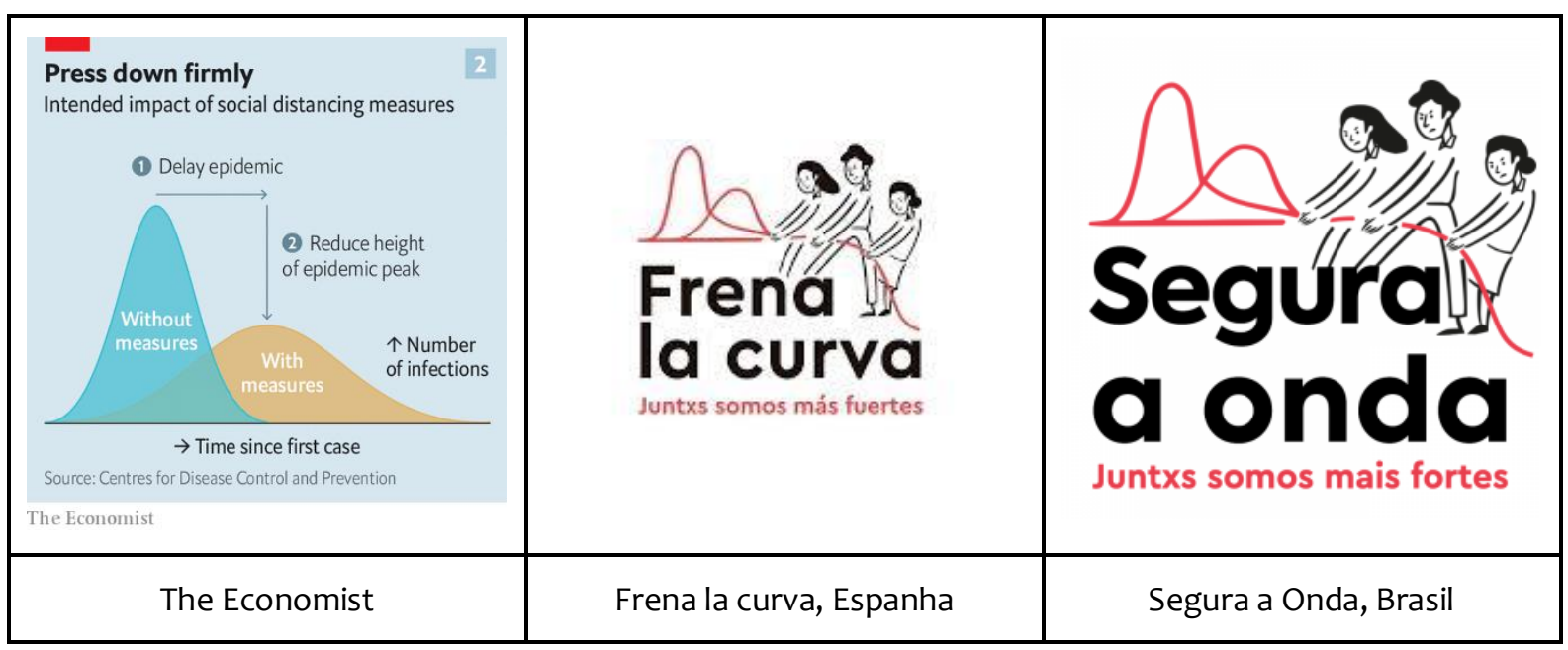




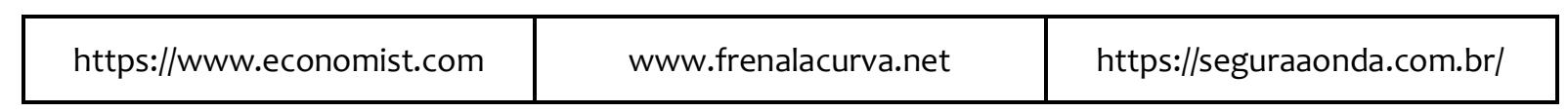

Fonte: elaboração própria

No Brasil, a ideia de "frear a curva" foi transposta como "Segura a Onda", adaptandose ao contexto cultural local e aproveitando-se de uma expressão familiar e consagrada. O domínio www.seguraaonda.com.br foi então registrado no dia 19 de março pelo Instituto Procomum e a hospedagem da plataforma foi cedida pela empresa Task Internet. Entre o registro do site e o lançamento da plataforma, foram apenas nove dias para reunir materiais, produzir documentos base, estruturar um ambiente de trabalho multiplataformas, definir rotinas, convidar e reunir pessoas dispostas a se engajar e colaborar.

\section{Articulação com a Rede Internacional Frena La Curva}

Como mencionado anteriormente, a plataforma Segura a Onda se formou como um capítulo da Rede Frena La Curva (Rede FLC) criada na Espanha a partir do Laboratório Aragão de Governo Aberto (LAAAB), uma área voltada à participação cidadã da administração pública da Comunidade Autônoma de Aragão. A plataforma espanhola foi lançada no dia 14 de março, data que marca o início do lockdown na Espanha, com 6.391 casos da doença, apenas dois dias após sua idealização, e rapidamente foi replicada em 18 países entre Europa, América Latina e América Central e Caribe ${ }^{12}$. Segundo Raúl Oliván, diretor do LAAAB, ainda não havia consciência da dimensão que a pandemia adquiriria, mas já se observava a mobilização cidadã espontânea e independente das ações governamentais, pressentindo que a onda de mobilização cidadã precisaria de uma ferramenta adequada para canalizar a energia social prestes a brotar. Em suas palavras:

No dia seguinte, nos dedicamos a formar alianças com empresas entidades sociais e ativistas, hackers... A ideia era construir uma plataforma o mais aberta possível. (...) O objetivo consistia em criar um pool de empresas, ativistas, organizações sociais e governo para orquestrar uma ação frente à crise da pandemia. A plataforma deveria canalizar a energia social, a resiliência cívica e a inovação social para dar uma resposta a partir da sociedade civil, o mais coordenada e coesa possível, além de complementar a estratégia do governo (Oliván, 2020).

Ao impulsionar a rede, a equipe de coordenação espanhola definiu inicialmente o objetivo de "canalizar e organizar a energia social e a resiliência cívica frente a pandemia do Covid-19, dando uma resposta a partir da sociedade civil". E as suas estratégias de implementação seriam: 1) criação e manutenção de uma estrutura de fórum $^{13}$ que compila numa tipologia adequada as informações sobre as múltiplas iniciativas cidadãs, 2) promoção de ações diretas como a organização de laboratórios cidadãos e desenvolvimento de $\operatorname{projetos}^{14}$ e, 3) a disponibilização de mapa

\footnotetext{
${ }^{12}$ São eles: Espanha, Portugal, França, Polônia Alemanha (a partir de imigrantes espanhóis no país), Colômbia, México, Equador, Venezuela, Uruguai, Brasil Argentina, Peru, Bolívia, Chile, Costa Rica, Guatemala, Honduras e Panamá.

${ }^{13}$ Disponível em: https://actua.frenalacurva.net/. Acesso em 15 de agosto de 2020.

${ }^{14} \mathrm{~A}$ base espanhola em articulação com sua rede realizou atividades como os "Laboratorios Ciudadanos Distribuídos", os "Colaboratorios", "Desafíos Comunes" e "Festival FLC".
} 
georreferenciado para conectar as pessoas que precisam de ajuda com as pessoas que podem ajudar, coordenando a ação de voluntários.

A história da formação da rede internacional pode ser lida com mais detalhes no site de FLC Espanha ${ }^{15}$. Aqui, nos interessa destacar que a sua rápida replicação foi facilitada pela existência prévia da rede de laboratórios de inovação cidadã fomentada pela Secretaría General Iberoamericana (Segib). No processo de disseminação, a equipe da Espanha forneceu orientações e recomendações iniciais sobre a programação visual e linha editorial ${ }^{16}$ e ofereceu $o$ registro de um domínio padrão: "nomedopaís.frenalacurva.net". Além disso, o apoio à expansão da rede se expressava na realização de reuniões semanais para compartilhamento de experiências locais, notícias sobre a situação sanitária, identificação de possíveis cruzamentos entre iniciativas e debates sobre questões de ordem prática como soluções tecnológicas, estratégias comuns de comunicação e possibilidades de financiamento. No final de julho, as reuniões foram suspensas para reavaliação de objetivos e prioridades na medida em que vários países estão com a disseminação do vírus sob controle, enquanto outros, como o Brasil, seguem com uma curva ascendente de contágios e mortos.

\section{Principais estratégias de atuação}

A plataforma Segura a Onda foi oficialmente lançada em 27 de março com o objetivo de contribuir com as estratégias de contenção da curva de contágios pelo coronavírus enquanto dispositivo que reúne, sistematiza, dissemina e, em alguma medida, fortalece as experiências de auto-organização popular e cidadã em todo o território nacional ${ }^{17}$ frente ao caos informacional. Coincidentemente, no dia do seu lançamento, o país inaugurava seu primeiro hospital de campanha no estádio do Pacaembú.

A partir de três estratégias de implementação sugeridas na rede internacional, a Segura a Onda concentrou seus esforços em duas delas: 1) na criação e manutenção de fóruns temáticos e 2) na promoção de ações diretas como a organização de laboratórios cidadãos e desenvolvimento de projetos através de parceria ${ }^{18}$. A terceira estratégia, de disponibilização de mapas georreferenciado ${ }^{19}$ para conectar a demanda e a oferta de apoio entre cidadãos, é até o momento de difícil implementação por falta de recursos humanos e financeiros e segue em espera. Por outro lado, inovamos com a realização de lives a partir de junho como estratégia para promover debate sobre

\footnotetext{
15 https://frenalacurva.net/conocenos-frena-la-curva/

${ }^{16}$ Estas eram apenas sugestões, pois se consideravam a diferença de contexto e as realidades locais. Algumas iniciativas, como a brasileira, optaram inclusive por nomes que melhor dialogam com seus concidadãos como foi o caso da Polônia (Widzimy ou "Vemos e Agimos Juntos"), da França (Coconfinés ou "Coconfinados"), do Uruguai (Acá Estamos!) e Brasil (Segura a Onda).

17 Destacamos que a plataforma Segura a Onda não registra iniciativas empresariais, sobretudo de grandes empresas, que embora possam ter motivações solidárias, contam com muitos recursos e grande visibilidade.

${ }^{18}$ A base espanhola em articulação com sua rede realizou atividades como os "Laboratorios Ciudadanos Distribuídos", os "Colaboratorios", "Desafíos Comunes" e "Festival FLC".

19 Em outras implementações locais, o mapa georreferenciado foi criado com Ushahidi\#, uma aplicação de código aberto sobre uma base de OpenStreetMap, desenvolvido para mapear informações vitais em zonas de catástrofes. Ushahidi significa "testemunha" em Swahili e foi desenvolvido no Quênia durante um episódio de violência pós-eleições em 2008. Desde então vem sendo usado em crises humanitárias em todo o mundo. Durante a pandemia global de 2020 , iniciativas em muitos países aplicaram Ushahidi enfocando diferentes aspectos como mapear incidência de casos, exames realizados, recursos e necessidades de suprimentos médicos. Os mapas de FLC, seguindo o modelo espanhol, possuem quatro categorias de geolocalizações (necessidades, ajudas, intermediários e serviços públicos) cada qual com uma cor.
} 
temas registrados na plataforma, fomentar novas parcerias e articulações entre redes de colaboração. As lives contam com o apoio do Instituto Procomum ${ }^{20}$ que disponibiliza estrutura e apoio técnico. A sua programação até o momento abordou as "Contribuições de makers e hackers para a produção de Equipamentos de Proteção Individual (EPIs)" (26 de junho), a "Galeria-Memorial das Vítimas Fatais da Covid-19" (3 de julho) e "Mulheres na Pandemia" (dia 22 de julho) ${ }^{21}$, somando 421 visualizações no YouTube.

A Segura Onda é um repositório que adota o formato fórum, definido previamente pela experiência espanhola, cuja estruturação temática se inspirou na edição mexicana. Ela está permanentemente aberta à contribuição de todos e todas que desejam registrar uma iniciativa, demandando apenas um simples cadastro (nome de usuário e e-mail) para a publicação imediata de informação sobre uma iniciativa em um dos seus 15 fóruns temáticos e uma lista especial de oportunidades para doações criada a partir da tag homônima. Os fóruns são: Fontes Oficiais, Informação Confiável, Cuidados, Quarentena, Educação, Cultura, Trabalho e Renda, Redes de Consumo, Ciência e Tecnologia Aberta, Populações Ameaçadas, Redes de Solidariedade, Gênero, Moradia e Aluguel, Universidades Públicas e Agenda.

Para registro de uma iniciativa, o usuário cadastrado deve completar as informações de seis campos, a saber: título do tópico, descrição, tags, fórum, tipo de tópico e status do tópico.

\section{Imagem 2: Formulário de cadastro de iniciativas}

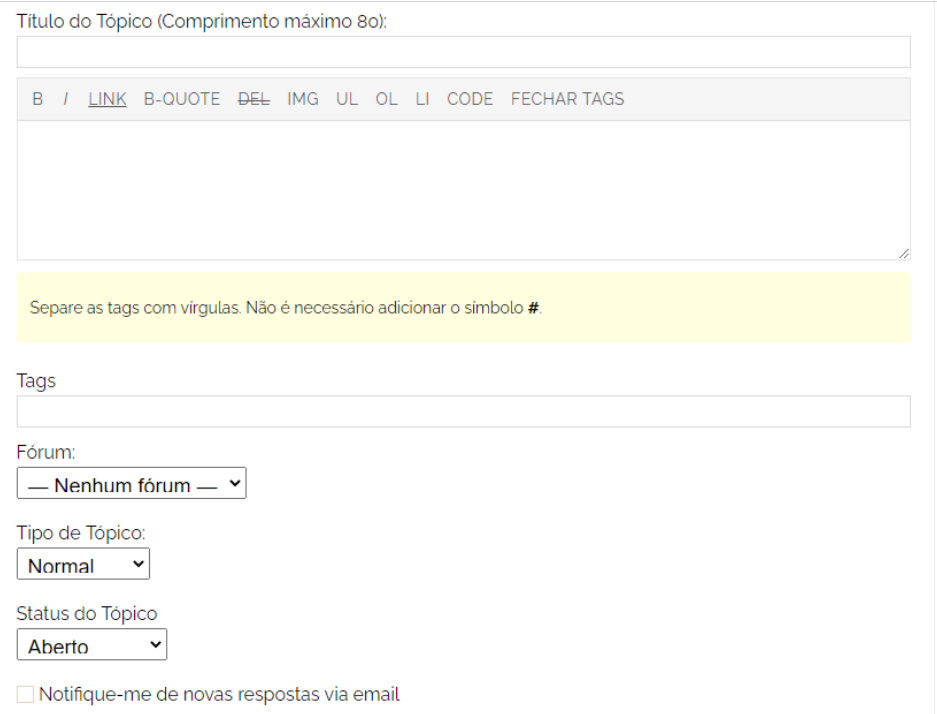

Fonte: Segura a Onda

O “Manual de Publicação" (Segura a Onda, 2020a) apresenta orientações básicas para os colaboradores, destacando a necessidade de inserção de palavras-chave como

\footnotetext{
${ }^{20} \mathrm{O}$ Instituto Procomum é um parceiro desde as etapas iniciais do projeto com o registro de domínio da plataforma, estratégia de divulgação do lançamento, entre outros apoios.

21 As lives estão disponíveis no canal do Youtube da Segura Onda, no endereço: https://www.youtube.com/channel/UC60FVnDSBPBg1Ymb4LFyA6A
} 
estratégia de indexação de conteúdo e base para a navegação pela plataforma, através da nuvem de tags localizada na barra à esquerda. Naquele momento, estudava-se a implementação de mapa, tal qual outros capítulos, e, por isso, foi dada ênfase à indexação por localização geográfica das iniciativas, criando-se inclusive um padrão. Após a sua livre inserção por usuários cadastrados, as contribuições são revisadas por moderadores voluntários que podem solicitar complementação ou até retirar publicações que desrespeitam os termos de uso da plataforma - especialmente sensível a iniciativas comerciais ${ }^{22}$, tentativas de disseminação de desinformação e fake news. Na primeira quinzena de agosto de 2020, a plataforma agrega 227 usuários registrados e 394 tópicos publicados ${ }^{23}$.

De acordo com o texto introdutório sobre a atividade de moderação (Segura a Onda, 2020b), disponibilizado na própria plataforma, os voluntários que realizam essa tarefa devem ter algum conhecimento e envolvimento com o tema do fórum, podendo publicar conteúdos relevantes e moderar contribuições de outras pessoas. Os moderadores devem zelar pela qualidade do debate e das interações, evitando que conteúdo impróprio seja publicado na plataforma. Suas principais atividades são:

- Editar tópicos e respostas: Aplicado quando um colaborador utiliza linguagem inapropriada, publica informações particulares, viola termos de uso ou para correção de erros de digitação que alteram completamente o significado da postagem.

- Mover tópicos entre fóruns: Quando verificam que um tópico está no lugar errado ou quando o próprio autor solicitar através do botão de "denunciar".

- Fechar tópicos: Quando a postagem é considerada improdutiva para a comunidade, quando viola os termos de uso ou se distancia drasticamente do tópico inicial. O moderador deve justificar o fechamento da postagem.

- Remover tópicos: Algumas situações demandam o arquivamento de postagens, ocultando-as do público como, por exemplo, o envio de spam, reincidência de violação por um colaborador dos termos de uso da plataforma, questões legais ou casos de assédio.

- Spam e abuso: Tais situações devem ser comunicadas pelos colaboradores, a partir do botão "denunciar" alertando os moderadores.

- Consolidar e corrigir tags: Prezar que a política de tags seja implementada mesmo quando os colaboradores não aplicam corretamente ou se esquecem de incluir palavras-chave, incluindo aquelas que indicam sua localização física ou virtual através da tag “web”.

\section{Fóruns temáticos}

Dos 15 fóruns temáticos da Segura a Onda, registrou-se em agosto de 2020 a seguinte distribuição das contribuições:

\footnotetext{
${ }^{22}$ Destacamos que a plataforma Segura a Onda não registra iniciativas empresariais, sobretudo de grandes empresas, que embora possam ter motivações solidárias, contam com muitos recursos e grande visibilidade.

23 Dados do dia 15 de agosto de 2020.
} 
Fontes oficiais - "Aqui você encontra as fontes de informações oficiais das autoridades nacionais e internacionais"

Informação Confiável - "Informações úteis sobre a pandemia de coronavírus e dicas sobre o combate às fake news."

Cuidados - "Conselhos e iniciativas de autocuidado e os cuidados aos demais durante a pandemia."

Quarentena - "Conselhos e recursos para o tempo em que estiver de isolamento ou quarentena em casa."

Educação - “Conselhos e materiais para ensinar e aprender durante o período de pandemia."

Cultura - "Iniciativas artístico-culturais em tempo de pandemia."

Trabalho e renda - "Informações e iniciativas que ajudem a enfrentar a crise do trabalho e renda."

Redes de consumo - Compra direta de produtores, redes de consumo solidário, microempreendedores e pequenos comércios.

Ciência e Tecnologia Aberta - Pesquisa e desenvolvimento de tecnologias e equipamentos para saúde ou para produção social.

Populações Ameaçadas - "Iniciativas que buscam fortalecer as populações com direitos ameaçados"

Redes de Solidariedade - "Aqui você encontra mobilizações organizadas por grupos de pessoas de forma independente."

Gênero - "Informações e iniciativas sobre questões de gênero relacionadas à pandemia e à quarentena."

Moradia e aluguel - "Problemas com o aluguel? Iniciativas de negociação, moratória, de organização coletiva pelo direito à moradia."

** Universidades Públicas - "As universidades públicas têm desempenhado papel fundamental no combate à pandemia. Saiba o que estão fazendo"

Agenda - "Mesmo durante a quarentena os eventos acontecem, em vários formatos, não só virtuais, mas também desde as janelas e até mesmo paredes dos prédios."

** Doações - "Separamos uma lista de campanhas em andamento para doações de todo tipo. Você pode doar desde máscaras, álcool gel, até mesmo dinheiro ou tempo."

Fonte: elaboração própria. Dados de 15/08/2020.

O tema de maior destaque na plataforma é o de "doações" que, por estar presente em diversos fóruns e ter caráter emergencial, motivou a criação de uma lista específica para facilitar o acesso. Outros destaques de conteúdo são: 


\section{Populações Ameaçadas ${ }^{24}$}

Agrega referências de iniciativas populares que buscam mitigar em certa medida os efeitos da pandemia sobre a saúde e a renda das populações mais vulneráveis. A Frente de Mobilização da Maré ${ }^{25}$, no Rio de Janeiro, e a autogestão da crise sanitária pela comunidade de Paraisópolis, em São Paulo, são exemplos paradigmáticos dessa mobilização cidadã. Uma parte importante dessa atuação comunitária está relacionada diretamente com a comunicação, através da criação de canais com o objetivo de esclarecer e orientar as pessoas sobre a importância do isolamento social e das medidas sanitárias, além de cobertura jornalística sobre os impactos da pandemia nas comunidades feita pelos próprios moradores ${ }^{26}$.

Também estão listadas neste fórum campanhas de redes de apoio aos povos indígenas de diferentes regiões do país, afetados de múltiplas formas pela pandemia. Além de sua maior vulnerabilidade imunológica, sofrem maior impacto por conta de condições sociais e econômicas mais precárias. Se todas as famílias perderam a dimensão social dos rituais de despedida, eliminados por razões sanitárias justificadas, as comunidades indígenas sofrem ainda mais por serem impedidas de realizar seus funerais de acordo com sua cultura. Soma-se a isso ainda o fato de que várias lideranças indígenas foram vitimadas pela doença, o que representa uma grande perda para sua memória coletiva.

\section{Ciência e Tecnologia Aberta ${ }^{27}$}

Logo no início da pandemia no Brasil, uma das maiores preocupações era a carência de equipamentos de proteção individual (EPIs) e respiradores para atender à crescente demanda, dificultada ainda mais pela disputa internacional na compra de suprimentos médicos. O fórum "Ciência e Tecnologia Aberta" ${ }^{28}$ foi criado para registrar as iniciativas de hackerspaces, makerspaces e fablabs, assim como de laboratórios de universidades, de prototipagem e produção de equipamentos. Nosso interesse era registrar projetos que tinham aderido aos princípios de design e hardware aberto. Isto é, cuja produção estava liberada das barreiras da propriedade intelectual a fim de que pudessem ser reproduzidos por outros centros.

O subfórum "Desenvolvimento e produção tecnológica" traz dados sobre repositórios de instrumentação técnica, prototipação de tecnologias abertas para produção de EPI's, respiradores, máscaras, arquivos para corte e impressão 3D. Já o subfórum "Iniciativas de inovação aberta para o desenvolvimento de equipamentos médicos" traz um mapeamento de iniciativas de universidades e espaços alternativos na produção de equipamentos médicos e de proteção.

\footnotetext{
24 O fórum agrega 62 tópicos em 6 subfóruns: 1) "Comunidades Indígenas", 2) "Comunidades Rurais", 3) “Imigrantes/Refugiados", 4) “Moradores das periferias e favelas urbanas", 5) “População carcerária” e 6) “População de rua".

${ }^{25}$ Mais informações em https://www.frentemare.com/

${ }^{26}$ Este é o caso, por exemplo, da iniciativa Maré de Notícias, promovida pelo Projeto Colabora em parceria com as Redes da Maré, para oferecer bolsas a jovens jornalistas de baixa renda moradores do Complexo da Maré. Mais informações em https://mareonline.com.br/.

27 O fórum agrega 43 tópicos em quatro subfóruns: 1) "Divulgação científica, 2) "Desenvolvimento e produção tecnológica", 3) "Convocatórias" e 4) "Iniciativas de inovação aberta para o desenvolvimento de equipamentos médicos"

${ }^{28}$ https://seguraaonda.com.br/foruns/forum/ciencia-e-tecnologia-aberta/
} 


\section{Gênero ${ }^{29}$}

Outro tema relevante é o problema da violência de gênero e doméstica, que aumentou significativamente durante a quarentena. Segundo o Fórum Brasileiro de Segurança Pública, o número de feminicídios no país cresceu 22,2\% em março e abril em 12 estados brasileiros, em relação ao mesmo período de 2019. São dados que revelam a importância de se ter informações organizadas e acessíveis para saber como agir nesses casos. Nesse sentido, o fórum de Gênero ${ }^{30}$ traz orientações e informações de iniciativas de apoio aos diferentes problemas enfrentados pelas mulheres durante a pandemia, como auxílio para alimentação, cuidado com os filhos e hospitais abertos para a prática de aborto legal. Dois subfóruns, "O que fazer em situações de violência doméstica" e "Redes e grupos de apoio" trazem referências de canais oficiais e redes de apoio mantidas por coletivos feministas. Destacamos as iniciativas que se focam em soluções tecnológicas pela dificuldade das mulheres saírem do isolamento social para realizar uma denúncia em delegacia especializada. Há ainda um terceiro subfórum, Direitos, com orientações jurídicas para situações que atingem diretamente a mulher durante a quarentena.

\section{Ações diretas: Apoio aos Laboratórios de Emergência e promoção da Galeria Memorial das Vítimas Fatais da Covid-19}

Dada as oportunidades de se associar a outras iniciativas, a Segura a Onda apoiou a divulgação das convocatórias de três edições do Laboratório de Emergência - Covid $19^{31}$ promovido pela Silo Arte e Latitude Rural ${ }^{32}$ de maio a agosto de 2020 . O laboratório objetiva apoiar o desenvolvimento de projetos voltados ao enfrentamento da pandemia, de forma colaborativa e com licenças livres que permitam sua replicação e adaptação a outros contextos.

Como ação direta propriamente dita, vale destacar a nossa atuação na promoção da Galeria-Memorial das Vítimas Fatais da Covid-19, surgida de parceria com a Rede de Apoio às Famílias das Vítimas de Covid-19 no Brasil, criada em março e que reúne cerca de 100 entidades, organizações não governamentais, movimentos sociais e profissionais autônomos. Iniciada através da página Segura a Onda - Brasil contra a Covid-19 no Facebook ${ }^{33}$, a Galeria-Memorial promove visibilidade àqueles que perderam a vida pelo novo coronavírus, mostrando que, por trás dos números frios anunciados diariamente nos telejornais, estão pessoas cujos rostos não podem ser esquecidos. Em segundo momento, a Galeria-Memorial se tornou um espaço para que os familiares possam homenagear seus mortos em um tempo em que os enterros são quase clandestinos e os rituais de luto são suprimidos, representando uma violência para as diferentes culturas. Soma-se a isso a tradução e publicação do "Guia para pessoas que perderam entes queridos em tempos de Covid" 34 , que traz orientações

\footnotetext{
29 O fórum agrega 33 tópicos em 3 subfóruns: 1) "O que fazer em situações de violência doméstica", 2) "Redes e grupos de apoio" e 3) "Direitos"

${ }^{30}$ https://seguraaonda.com.br/foruns/forum/genero/

${ }^{31}$ Mais informações em https://labdeemergencia.silo.org.br/. Acesso em 11 Ago. 2020.

${ }^{32}$ https://silo.org.br/

33 https://www.facebook.com/seguraaondaBR/

34 Disponível em: https://seguraaonda.com.br/wp-content/uploads/2020/05/guia-vitimas-final.pdf
} 
para familiares e sugestões para lidar com o luto durante a quarentena, disponibilizado na plataforma.

Embora seja impossível publicar homenagens a pessoas falecidas no ritmo em que as mortes acontecem no país, a Galeria-Memorial combate, em alguma medida, a desinformação oficial sobre o real impacto da pandemia, podendo no futuro próximo integrar ações de responsabilização de instâncias governamentais no enfrentamento da doença e processos de reparação de famílias. A Rede de Apoio às Famílias das Vítimas Fatais e o Memorial Vagalumes, que foca no impacto da pandemia entre os indígenas, são também parceiros fundamentais na alimentação da Galeria-Memorial. Aqui, vale ressaltar que o Memorial é a única iniciativa da rede Frena La Curva que lida com a questão do luto e das vidas perdidas - o que pode representar uma especificidade do desenvolvimento da pandemia no Brasil.

\section{A SEGURA ONDA COMO INICIATIVA CIDADÃ: ALGUMAS REFLEXÕES}

Se a Segura Onda é uma plataforma de visibilização de iniciativas da sociedade civil, ela também se constitui como uma iniciativa cidadã que enfrenta diariamente os limites da ação voluntária e sem apoio financeiro. Nesta seção, relatamos alguns desafios e lições aprendidas pelo grupo nestes meses de atuação, vislumbrando ser uma contribuição em futuros debates e pesquisas sobre os desafios da informação em situações de crise global.

Em primeiro lugar, é preciso destacar o tamanho da crise sanitária e a desproporcionalidade de recursos entre a atuação de grupos voluntários e outras ações com recursos. No início, a articulação entre os voluntários brasileiros se deu pela criação de um grupo local na ferramenta Telegram e chegou a reunir 61 membros. Atualmente, nossa equipe é composta por oito voluntários com diferentes formações e disponibilidade de tempo, divididos entre as seguintes tarefas: duas pessoas da área de tecnologia ficaram responsáveis pelo desenvolvimento da plataforma; uma assumiu a divulgação nas redes sociais; uma ficou responsável pela conexão com a rede Frena la Curva; uma ficou à frente da Galeria-Memorial; e os demais assumiram diferentes frentes de trabalho como a inserção e moderação de dados na plataforma, a realização de lives etc.

Do ponto de vista da organização interna, buscamos estruturar as atividades com ferramentas digitais gratuitas e, preferencialmente, livres. Da lista inicial do Telegram, migramos para a plataforma Slack, recomendada por um dos participantes. Foram criados diferentes canais para encaminhar as ações por áreas como tecnologia, conteúdo e marketing, entre outras. Um quadro de tarefas chegou a ser criado no aplicativo Trello com o objetivo de facilitar a gestão de atividades,mas a adesão ficou resumida à equipe de tecnologia que tinha maior familiaridade com a ferramenta. Nas primeiras semanas, as reuniões de equipe por videochamada eram diárias (sempre às 19h para não conflitar com horários de trabalho dos voluntários), mas posteriormente se tornaram semanais (aos sábados, às 14h), sempre usando a plataforma livre Jitsi. $\mathrm{Na}$ maioria das vezes, a pauta do encontro semanal gira em torno das atualizações do desenvolvimento de tarefas e tomada de decisões - por consenso construído após debate. Todos os encontros são registrados em atas que ficam arquivadas no subdiretório Brasil de um Google Drive que reúne informações de toda rede Frena La Curva. Além das atas, são arquivadas outras documentações como planejamento de atividades, referências, materiais de marketing etc. 
Com os recursos que tínhamos à mão, estruturamos as informações no formato fórum de discussões, tal qual realizado em outros países. A adequação do formato à cultura digital brasileira foi tema de debate entre os voluntários, pois vislumbrava-se que as redes sociais corporativas seriam um espaço de maior alcance. Neste sentido, buscamos divulgar as informações através das redes sociais Facebook, Twitter e Instagram a fim de nos comunicarmos com o público em potencial. No entanto, pela falta de financiamento, nunca pudemos impulsionar esses conteúdos e ficamos à mercê dos algoritmos, impostos especialmente pelo Facebook, que diminuem drasticamente a circulação de postagens não monetarizadas.

Em relação ao acervo, a plataforma registra em 15 de agosto, 175 iniciativas promovidas por coletivos, movimentos sociais e indivíduos, como por exemplo, profissionais de apoio à saúde mental. Em relação aos movimentos sociais, observamos que, em boa parte dos casos, os coletivos se desdobram em várias iniciativas ao longo do tempo. Às vezes trata-se de uma rede de iniciativas, como a Frente de Mobilização da Maré, que reúne 14 coletivos e conta com o apoio de 20 entidades. No caso de instituições formais, como fundações e institutos, temos 40 iniciativas cadastradas, que por vezes atuam em mais de uma iniciativa. Há ainda o registro de 40 iniciativas de universidades e instituições de pesquisa, levando as palavras-chave "universidade" e "universidade pública" a se destacarem na nuvem de tags da plataforma.

No que se refere ao alcance da iniciativa, o maior número de acessos foi no dia seguinte ao lançamento, quando chegamos a 4.392 visualizações de páginas. Nos primeiros 30 dias, de 27 de março a 25 de abril, tivemos um total de 24.725 visualizações. Aos poucos, percebemos que a afluência de visitantes na plataforma foi diminuindo. Nos últimos 30 dias, de 17 de julho a 15 de agosto, os números de visualizações caíram para 3.088, com um pico de 354 visualizações no dia 9 de agosto, resultado de uma campanha pelos 100 mil mortos por Covid-19 no Brasil. A ponto de completar cinco meses, as páginas da plataforma estão com cerca de 40 mil visualizações ${ }^{35}$. A partir das estatísticas de visitação, observamos que a busca por informações qualificadas foi mais evidente no início da pandemia quando boa parte da população buscava compreender a doença, conhecer os procedimentos para evitar o contágio e acessar informações úteis sobre como lidar na vida prática com outros impactos do isolamento social.

\section{Imagem 3: Estatísticas do site}

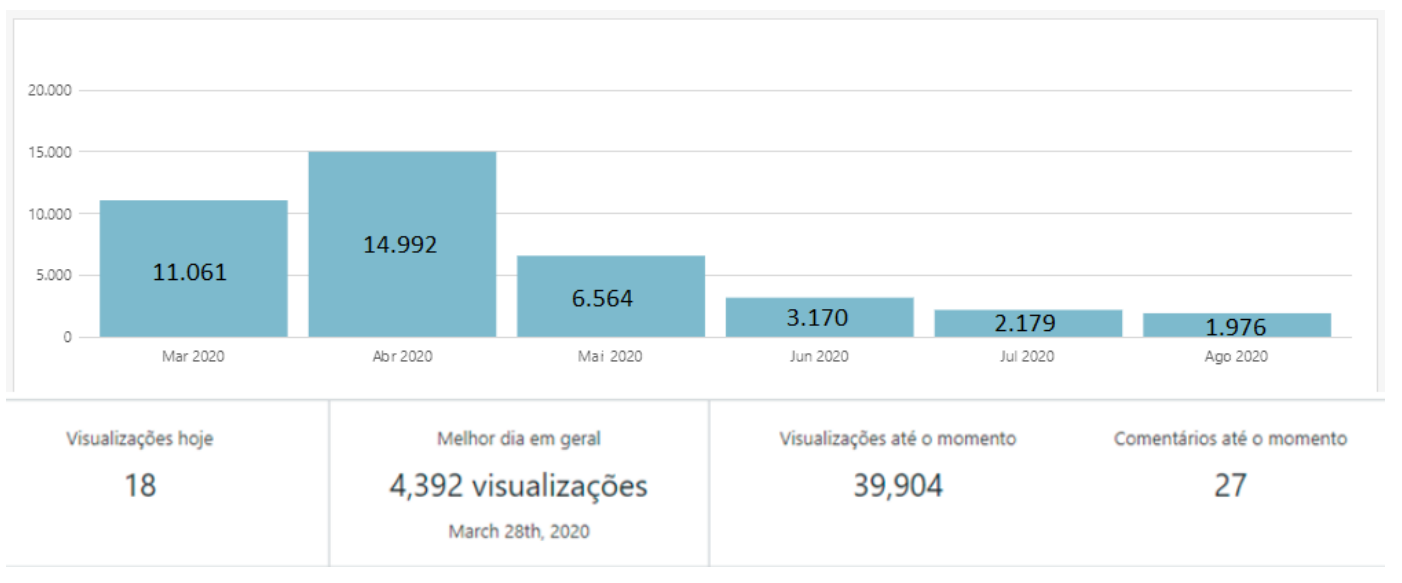

35 Todos os dados deste tópico correspondem ao dia 15 de agosto de 2020. 
Em parte, avaliamos que os resultados alcançados podem ter sido ocasionados pelo fato de que os brasileiros não estão tão familiarizados com o formato de fórum de discussão e preferirem as interações em redes sociais. Esta percepção é reforçada pelo dado da plataforma registrar apenas 27 comentários ao longo do período. As pessoas visualizam o conteúdo e clicam nos links divulgados nos tópicos, mas não aderem à discussão proposta pelo formato fórum. Por conta disso, chegamos a pensar em desenvolver uma interface de navegação diretamente no mapa, como faz a edição espanhola, mas não obtivemos êxito para o seu financiamento até o momento.

Por outro lado, a Galeria-Memorial mantém boa repercussão, sendo até agora um dos pontos mais bem-sucedidos da plataforma - o que revela o peso social da falta dos rituais de luto, exigido pelas medidas sanitárias, que deixou como uma ferida em aberto para quem perdeu familiares e amigos. A postagem com maior número de visitas na plataforma até agosto de 2020, com 1.724 visualizações, é sobre a criação da Rede de Apoio às Famílias de Vítimas Fatais do Covid-19 no Brasil ${ }^{36}$. Outra postagem do Memorial, sobre a morte de um médico, branco, de 32 anos, foi a que teve maior alcance na página Segura a Onda - Brasil Contra a Covid-19, no Facebook, atingindo 10.365 pessoas. A desproporcionalidade da repercussão frente a outros personagens indica a possibilidade de futuras pesquisas sobre que perfis de vítimas do coronavírus geram maior empatia do público a partir de informações básicas como foto, idade e profissão.

\section{CONSIDERAÇÕES FINAIS}

Como dito anteriormente, a plataforma Segura Onda é um dos muitos mapeamentos de iniciativas cidadãs produzidos durante a pandemia do coronavírus no país com objetivo de dar visibilidade às ações cidadãs, e combater a desinformação a partir da oferta de informações confiáveis, elaboradas por fontes relevantes e verificadas, em alguma medida, por moderadores voluntários.

Se, notadamente, o enfrentamento eficaz da pandemia depende da articulação de diversos atores sociais, a informação qualificada é a base necessária para a coordenação das suas ações. Segundo nossa experiência, organizar um repositório com informações relevantes é um passo importante para o enfrentamento de crises de grande escala, mas outras ações complementares são necessárias para garantir o alcance de público e o impacto social desejado. Conforme descrito na seção anterior, são muitos os fatores que geraram resultados modestos da Segura a Onda, destacando-se as limitações de recursos humanos e financeiros, a inadequação do formato fórum para o público brasileiro, a obstacularização do livre fluxo da comunicação pelos algoritmos das redes sociais corporativas e sua demanda por verbas para impulsionamento de conteúdos etc.

Apesar dos resultados reduzidos, acreditamos que nossa experiência sinaliza os desafios a serem enfrentados por grupos que, no futuro, optem pelo mapeamento de iniciativas como estratégia para o enfrentamento de novas situações de crise em larga escala. Além disso, a documentação produzida ao longo dos últimos meses, pode ser fonte de informação para pesquisas sobre os processos de organização de iniciativas

${ }_{36}$ Disponível em: https://seguraaonda.com.br/nasce-a-rede-de-apoio-as-familias-de-vitimas-fatais-do-covid-19-nobrasil/ 
comunitárias que optam pela informação como base da sua intervenção. Do ponto de vista do acervo reunido e organizado na plataforma on-line, identificamos que o registro das iniciativas cidadãs contribuem para a construção da memória sobre as ações da sociedade civil que nem sempre estampam os jornais. Por fim, a GaleriaMemorial das Vítimas Fatais do Covid-19, especialmente as homenagens escritas pelos familiares e amigos de falecidos, podem, no futuro, integrar ações de responsabilização de instâncias governamentais em processos de reparação.

Neste momento, em que o fim da crise sanitária ainda é um horizonte longínquo, os voluntários da Segura a Onda estão realinhando suas expectativas pessoais para, a partir da Teoria da Mudança ${ }^{37}$, identificar disponibilidade e as habilidades com que podemos contar para, avaliar estratégias de ação e planejar os próximos passos.

\section{REFERÊNCIAS}

CENTERS FOR DISEASE CONTROL AND PREVENTION (U.S.). Interim pre-pandemic planning guidance: community strategy for pandemic influenza mitigation in the United States: early, targeted, layered use of nonpharmaceutical interventions. 2017. Disponível em: https://stacks.cdc.gov/view/cdc/11425. Acesso em: 12 ago. 2020.

CHADE, Jamil. Com mais casos que EUA em 14 dias, Brasil se consolida como epicentro. UOL, 05 jun. 2020. Disponível em:

https://noticias.uol.com.br/colunas/jamil-chade/2020/06/05/com-mais-casos-que-euaem-14-dias-brasil-se-consolida-como-epicentro.htm. Acesso em: 12 ago. 2020.

DANTAS, Carolina. Cientistas do Brasil e de Oxford sequenciam genoma do novo coronavírus detectado em SP. G1, 28 fev. 2020. Disponível em: https://g1.globo.com/bemestar/coronavirus/noticia/2020/02/28/cientistas-do-brasil-ede-oxford-sequenciam-genoma-do-novo-coronavirus-detectado-em-sp.ghtml. Acesso em: 15 ago. 2020.

MELO, Maria Luisa de. Primeira vítima do RJ era doméstica e pegou coronavírus da patroa no Leblon. UOL, 19 mar. 2020. Disponível em: https://noticias.uol.com.br/saude/ultimas-noticias/redacao/2020/03/19/primeira-vitimado-rj-era-domestica-e-pegou-coronavirus-da-patroa.htm. Acesso em: 12 ago. 2020.

NERY, Carmen. Extrema pobreza atinge 13,5 milhões de pessoas e chega ao maior nível em 7 anos. Agência IBGE Notícias, 06 de nov. 2019. Disponível em: https://agenciadenoticias.ibge.gov.br/agencia-noticias/2012-agencia-denoticias/noticias/25882-extrema-pobreza-atinge-13-5-milhoes-de-pessoas-e-chega-aomaior-nivel-em-7-anos. Acesso em: 12 ago. 2020.

OLIVÁN, Raúl. El objetivo de Frena la curva es canalizar la energía social. [Entrevista concedida a] Mario Gracia. Espacio3, 08 abr. 2020. Disponível em: https://www.elperiodicodearagon.com/noticias/espacio3/objetivo-frena-curva-escanalizar-energia-social_1417188.html. Acesso em: 12 ago. 2020.

\footnotetext{
37 Construção de um modelo descritivo para explicar a razão por trás dos resultados desejados, identificando por que são necessários, como serão alcançados e monitorados. (http://www.theoryofchange.org/wpcontent/uploads/toco_library/pdf/ToC-Tech-Papers.pdf)
} 
RIBEIRO, Marcela. Coronavírus: quem é a irmã de Pugliesi que fez casamento luxuoso na Bahia. UOL, 13 mar. 2020. Disponível em:

https://tvefamosos.uol.com.br/noticias/redacao/2020/03/13/saiba-quem-e-a-irma-depugliesi-que-fez-um-casamento-milionario-na-bahia.htm. Acesso em: 12 ago. 2020.

SEGURA A ONDA. Manual de publicação. 2020a. Disponível em:

https://seguraaonda.com.br/foruns/topico/manual-de-publicacao. Acesso em: 10 ago. 2020.

SEGURA A ONDA. Moderação. 2020b. Disponível em:

https://seguraaonda.com.br/foruns/topico/moderacao. Acesso em: 10 ago. 2020.

THE ECONOMIST. Covid-19 is now in 50 countries, and things will get worse. The Economist, 29 fev. 2020. Disponível em

https://www.economist.com/briefing/2020/02/29/covid-19-is-now-in-50-countries-andthings-will-get-worse. Acesso em: 12 ago. 2020. 